\title{
OUR INTUITIONS ABOUT THE EXPERIENCE MACHINE
}

\author{
Richard Rowland
}

\begin{abstract}
T Elipe de brigard, Adam Kolber, Wayne Sumner, Dan Weijers, and - Katarzyna de Lazari-Radek and Peter Singer have argued that our intuI itions about Nozick's experience machine are untrustworthy because they are distorted by biases and irrelevant factors. De Brigard and Weijers recently conducted empirical studies regarding people's intuitions about versions of the experience machine to test which of our intuitions are not distorted by such biases and irrelevant factors. They claim their results show that our intuitions about the experience machine do not undermine hedonism (section I). I argue, on the basis of further empirical studies, that De Brigard and Weijers fail to establish that our intuitions about the experience machine do not undermine hedonism (section II).

Hedonism is the view that the only thing that is noninstrumentally good for us or that noninstrumentally improves our well-being is pleasure. Nozick famously asked us to consider the following thought experiment:
\end{abstract}

Suppose there were an experience machine that would give you any experience you desired. Superduper neuropsychologists could stimulate your brain so that you would think and feel you were writing a great novel, or making a friend, or reading an interesting book. All the time you would be floating in a tank, with electrodes attached to your brain. Should you plug into this machine for life, preprogramming your life's experiences? ${ }^{1}$

Nozick presumed that upon considering the experience machine the vast majority of people would judge that they should choose to remain in reality rather than plug into the machine, and that this gives us strong reason to reject hedonism. And our intuitions about Nozick's experience machine are widely held to give us strong reason to reject hedonism. 
De Brigard, Kolber, Sumner, Weijers, and Lazari-Radek and Singer argue that our intuitions about Nozick's experience machine are prone to some of the following misleading factors and biases:

(a) Imaginative resistance to the possibility of such an experience machine, such as worries that the machine might not work as well as we think it does.

(b) The fact that we find it hard to give up responsibility for our loved ones in the way that we must if we plug into the experience machine.

(c) Overactive imaginations overreacting to the scenario and being overly horrified by Nozick's characterization.

(d) Status quo bias - that is, an inappropriate or irrational preference for an option because it preserves the status quo. ${ }^{2}$

According to these philosophers, the fact that our intuitions about the experience machine are prone to (a)-(d) directly or indirectly establishes that these intuitions do not give us strong reason to reject hedonism. ${ }^{3}$

This argument is made most strongly and plausibly by De Brigard and Weijers, who each develop versions of the experience machine our intuitions about which are supposedly not prone to (a)-(d). Call De Brigard's and Wejiers's versions of the experience machine Undistorted Experience Machines. De Brigard and Weijers conducted studies of people's intuitions about Undistorted Experience Machines and Nozick's experience machine. They found that, although a majority judge that we should choose reality rather than Nozick's experience machine, it is not the case that a majority judge that we should choose reality rather than an Undistorted Experience Machine. De Brigard and Weijers conclude that this shows that our intuitions about the experience machine do not give us strong reason to reject hedonism.

In De Brigard's Undistorted Experience Machine cases, we are asked to imagine being told by a reliable source that we have been living life inside an experience machine and are given the chance to unplug to lead a different life in reality. De Brigard's cases are intended to prevent status quo bias from influencing our

2 See Bostrom and Ord, "The Reversal Test: Eliminating Status Quo Bias in Applied Ethics."

3 See De Brigard, "If You Like It, Does It Matter If It's Real?"; Kolber, "Mental Statism and the Experience Machine," 13-16; Sumner, Welfare, Happiness and Ethics, 21; Weijers, "Intuitive Biases in Judgments about Thought Experiments" and "Nozick's Experience Machine Is Dead, Long Live the Experience Machine!" $517-19$; and Lazari-Radek and Singer, The Point of View of the Universe, 254-61. 
anti-experience-machine intuitions. ${ }^{4}$ But they succeed in this endeavor at the cost of rendering pro-experience-machine intuitions prone to status quo bias; for in De Brigard's cases, the status quo is the experience machine. ${ }^{5}$

Weijers's Undistorted Experience Machine avoids this problem. In Weijers's Undistorted Experience Machine, we are asked to consider the following case:

A stranger, named Boris, has just found out that he has been regularly switched between a real life and a life of machine-generated experiences (without ever being aware of the switches); 50\% of his life has been spent in an Experience Machine and 50\% in reality. Nearly all of Boris' most enjoyable experiences occurred while he was in an Experience Machine and nearly all of his least enjoyable experiences occurred while he was in reality. Boris now has to decide between living the rest of his life in an Experience Machine or in reality (no more switching).

You have had a go in an Experience Machine before and know that they provide an unpredictable rollercoaster ride of remarkable experiences. When in the machine, it still felt like you made autonomous decisions and occasionally faced tough situations, such as striving for your goals and feeling grief, although you didn't really do these things. Your experiences were also vastly more enjoyable and varied in the machine. You also recall that, while you were in the Experience Machine, you had no idea that you had gotten into a machine or that your experiences were generated by a machine.

Boris' life will be the same length in an Experience Machine as it would in reality. No matter which option Boris chooses, you can be sure of two things. First, Boris' life will be very different from your current life. And second, Boris will have no memory of this choice and he will think that he is in reality.

(1) Ignoring how Boris' family, friends, any other dependents, and society in general might be affected, and assuming that Experience Machines always work perfectly, what is the best thing for Boris to do for himself in this situation? Tick only one of these options:

Boris should choose the Experience Machine life.

Boris should choose the real life.

(2) Briefly explain your choice. ${ }^{6}$

4 De Brigard, "If You Like It, Does It Matter If It's Real?" 47-50.

5 Weijers, "Nozick's Experience Machine Is Dead, Long Live the Experience Machine!" 519.

6 Weijers, “Nozick's Experience Machine Is Dead, Long Live the Experience Machine!” 525-26. 
Weijers gave eighty-two subjects his Undistorted Experience Machine. Of those eighty-two, 54.5 percent said that Boris should choose the experience machine life. ${ }^{7}$ Weijers also asked seventy-nine subjects about Nozick's original version of the experience machine and found that, in comparison, only 16 percent would plug into Nozick's machine. ${ }^{8}$ On the basis of this survey data, Weijers concludes that our intuitions about the experience machine do not give us strong reason to reject hedonism. ${ }^{9}$ For once we eliminate factors that distort our intuitions about the experience machine, a majority of people do not have the intuition that a life in reality is better for us than a life in the experience machine. ${ }^{10}$

In Weijers's Undistorted Experience Machine, all other things are not held equal between the experience machine life and the real life: life in the experience machine is far more pleasurable and exciting than real life. Given that all things are not held equal in Weijers's case, it is consistent with Weijers's results that all 54 percent-or at least a significant proportion of the 54 percent - who responded to Weijers's vignette by saying that Boris should choose the experience machine life believe, or are inclined to believe:

Pleasure-Weighted Non-Hedonism: Pleasure is not all that is noninstrumentally good for us; other things, such as living a life in reality, are noninstrumentally good for us too. But a life of great pleasure that is not in reality is better for us than a life of far less pleasure in reality because the noninstrumental goodness for us of pleasure is greater than the noninstrumental goodness for us of any other good.

As I explain, Pleasure-Weighted Non-Hedonism is a plausible view that many people hold.

To see the plausibility of Pleasure-Weighted Non-Hedonism, suppose that you lead an utterly miserable life of pain and suffering, alone, achieving nothing. You know that you cannot escape this life of torment and pain while remaining in reality. But you have the ability to plug into an experience machine that will give you the immensely enjoyable experience of living a very pleasurable life. We can certainly think that living a life in reality is noninstrumentally good for us, but that a life in reality in this case is so bad that it would be preferable and better for

7 Weijers, “Nozick's Experience Machine Is Dead, Long Live the Experience Machine!” 527.

8 Weijers, "Nozick's Experience Machine Is Dead, Long Live the Experience Machine!" 520.

9 Weijers, “Nozick's Experience Machine Is Dead, Long Live the Experience Machine!” 529.

10 Weijers, “Nozick's Experience Machine Is Dead, Long Live the Experience Machine!" 528-29. 
us to plug into the experience machine. And some of De Brigard's experimental results favor the view that many hold Pleasure-Weighted Non-Hedonism. For 87 percent of De Brigard's participants preferred staying in the experience machine to a life full of very little pleasure (in a maximum security prison) but only 50 percent of people preferred a life in the experience machine to a very pleasurable life (as a millionaire in Monaco). The combination of De Brigard's results favors the view that many hold Pleasure-Weighted Non-Hedonism because the view that many hold that the goodness for us of pleasure is greater than the goodness for us of contact with reality. This can explain why so many more people prefer the experience machine to the unpleasant prison life than preferred the experience machine life to the pleasurable millionaire life. ${ }^{11}$

So it seems that if we want to truly test whether people's intuitions about the experience machine count against hedonism, we must investigate their intuitions about an Undistorted Experience Machine case in which all things are held equal between the two lives we are able, or another is able, to choose. (Many other philosophers, including Russ Shafer-Landau in his widely used introductory text, and prominent hedonists such as Roger Crisp, also focus on versions of the experience machine thought experiment in which all things are held equal between the experience machine life and the life in reality. $)^{12}$ I developed such an Undistorted Experience Machine and ran an experimental survey using it.

I recruited eighty-one subjects from Amazon's Mechanical Turk platform. I gave the subjects a variation of Weijers's vignette in which a life in the experience machine was stipulated as being predictably only as enjoyable as a life in reality. I gave subjects the following vignette and questions (italics denote changes from Weijers's vignette; these italics were not in the version subjects were given):

A stranger, named Boris, has just found out that he has been regularly switched between a real life and a life of machine-generated experiences (without ever being aware of the switches); $50 \%$ of his life has been spent in an Experience Machine and 50\% in reality. 50\% of Boris' most enjoyable experiences occurred while he was in an Experience Machine and 50\% of his most enjoyable experiences occurred while he was in reality. Boris now has to decide between living the rest of his life in an Experience Machine or in reality (no more switching). Living in the Experience Machine rather than in reality will not make Boris happier and Boris knows this before making his 
choice; if Boris chooses a life outside of an Experience Machine his life will be as happy as his life would have been had he chosen a life in an Experience Machine. If Boris does not choose one of these two new forms of life he will not continue living. Boris must make an active choice between these two new lives. And he will not remember having made his choice once he begins his new life.

You have had a go in an Experience Machine before and know that they are extraordinarily safe and can provide remarkable experiences. When in the machine, it still felt like you made autonomous decisions and occasionally faced tough situations, such as striving for your goals and feeling grief, although you didn't really do these things. You felt that your life, plans, relationships, and achievements were real. You also recall that, while you were in the Experience Machine, you had no idea that you had gotten into a machine or that your experiences were generated by a machine.

Boris' life will be the same length in an Experience Machine as it would in reality. No matter which option Boris chooses, you can be sure of four things. First, Boris' life will be very different from your current life. Second, Boris will have no memory of this choice and he will think that he is in reality. Third, the experience machine will not malfunction or break when Boris is in it. Fourth, Boris' life will be as long and happy as it would have been had he made the alternative choice.

(1) Ignoring how Boris' family, friends, any other dependents, and society in general might be affected, and assuming that Experience Machines always work perfectly, what is the best thing for Boris to do for himself in this situation? Tick only one of these options:

Boris should choose the Experience Machine life.

Boris should choose the real life.

(2) Briefly explain your choice.

Of the eighty-one subjects, seventy-three-more than 90 percent-said that Boris should choose the real life; only eight subjects-less than 10 percentsaid that Boris should choose the experience machine life. (Furthermore, seven of the eight subjects who said that Boris should choose the experience machine life explained their choice in a way that showed that they had either accidentally ticked the option that they did not mean to tick or believed that life in the experience machine would be safer or more pleasurable. $)^{13}$

13 An anonymous referee points out that a convinced hedonist might want to choose a third option that was not offered-namely that it does not matter which life Boris chooses. However, participants were asked to explain their choice. Of the seventy-three subjects who said 
So, De Brigard and Weijers are mistaken that experimental data regarding our intuitions about the experience machine establish the failure of the argument against hedonism from our intuitions about the experience machine, since, when all other things were held equal, more than 90 percent of subjects judged that we should, for the sake of what is good for us, choose a life in reality over a life in the experience machine. ${ }^{14}$ Furthermore, the argument that our intuitions about the experience machine do not give us strong reason to reject hedonism because our intuitions about the experience machine are subject to distorting biases seems to fail too. For when all these distorting and biasing factors were mitigated and all other things were held equal, the vast majority of people judged that we should, for the sake of what is good for us, choose a life in reality over a life in the experience machine. ${ }^{15}$

\author{
Australian Catholic University \\ richard.rowland@acu.edu.au
}

\title{
REFERENCES
}

Bostrom, Nick, and Toby Ord. "The Reversal Test: Eliminating Status Quo Bias in Applied Ethics." Ethics 116, no. 4 (July 2006): 656-79.

Crisp, Roger. Reasons and the Good. Oxford: Oxford University Press, 2006.

that Boris should choose the real life, only one said that they thought it made no difference which life Boris chose, such that they would have ticked a third box saying that Boris should flip a coin, if such an option had been provided. The fact that (i) only one of the seventy-three subjects who ticked the "Boris should choose the real life" option said that they would have chosen a "makes no difference" option combined with the fact that (ii) most subjects elucidated a view about how reality matters in itself in their explanation of their choice and the fact that (iii) we would expect subjects who thought it made no difference which life Boris picks to tick the reality or experience machine options with approximately equal frequency, provides good evidence that very few subjects would have chosen a "makes no difference" option if it had been presented.

14 Weijers, “Nozick's Experience Machine Is Dead, Long Live the Experience Machine!” 528 29, and De Brigard, "If You Like It, Does It Matter if It's Real?" 44.

15 I would like to thank the University of Oxford's John Fell Fund for generously funding this research. I would also like to thank Lucius Caviola, Dan Cohen, Roger Crisp, Guy Kahane, David Killoren, Tyler Paytas, and Dan Weijers for their advice and/or feedback regarding this article, the ideas within, and/or how to conduct the study for this article. And I would like to thank Sam Billington, whose undergraduate essay at Somerville got me thinking about the issues of this article. 
De Brigard, Felipe. "If You Like It, Does It Matter If It's Real?" Philosophical Psychology 23, no. 1 (2010): 43-57.

Kolber, Adam J. "Mental Statism and the Experience Machine." Bard Journal of Social Sciences 3 (1994): 10-17.

Lazari-Radek, Katarzyna de, and Peter Singer. The Point of View of the Universe: Sidgwick and Contemporary Ethics. Oxford: Oxford University Press, 2014.

Lin, Eden. "How to Use the Experience Machine." Utilitas 28, no. 3 (September 2016): 314-32.

Nozick, Robert. Anarchy, State, and Utopia. New York: Basic Books, 1974.

Shafer-Landau, Russ. The Fundamentals of Ethics. 2nd ed. Oxford: Oxford University Press, 2012.

Sumner, L.W. Welfare, Happiness and Ethics. Oxford: Oxford University Press, 1996.

Weijers, Dan. "Intuitive Biases in Judgments about Thought Experiments: The Experience Machine Revisited.” Philosophical Writings 41, no. 1 (2011): 17-31.

_ . "Nozick's Experience Machine Is Dead, Long Live the Experience Machine!" Philosophical Psychology 27, no. 4 (2014): 513-35. 